\title{
A survey of general hospital in-patients detained under Section 5(2) of the 1983 Mental Health Act
}

\author{
Christopher Buller, David Storer and Rachel Bennett
}

\begin{abstract}
Detention of general hospltal in-patients under Section $5(2)$ is a rare occurrence. This study of the use of Section 5(2) in general hospltals uncovered a frequent neglect in following the guidelines of the Mental Health Act and The Code of Practice. Surprisingly the conversion rate of Section 5(2) to Section 2 or 3 was simillar to that seen in a number of other studies conducted in the quitte different selting of large poychiatric hospltals. A number of patient characteristics were identified that appeared to influence whether 5(2)s were converted to an admission Section. Each general hospltal needs to develop guidelines to be followed when staff feel that a patient should be detained under Section 5(2) - an example of such a policy is included.
\end{abstract}

Over the last 5 years in the United Kingdom there have been a number of studies examining various aspects of the use of Section 5(2) of the Mental Health Act in large psychiatric hospitals (Joyce et al, 1991; Cooper, 1992; Pourgourides et al, 1992; Mason \& Turner, 1994). As far as the authors are aware this study is the first to investigate the use of Section $5(2)$ in general hospitals. It was prompted by concern that the frequency of its use was increasing at one of the hospitals involved in the study.

The specific aims of this audit were (a) to determine whether the Mental Health Act (Department of Health, 1983) and the Code of Practice (DoH, 1993) were being adhered to when general hospital in-patients are detained: (b) to ascertain if general hospital in-patients placed on a Section 5(2) are being appropriately managed, in particular do they receive regular psychiatric review; (c) to identify any common features among the patients that perhaps increased the likelihood of their detention under the Mental Health Act and, (d) to determine the medical and legal outcomes of patients placed on a Section 5(2).

\section{The study}

This case-series consisted of all in-patients detained on a Section 5(2) at two large inner-city teaching hospitals during a 5 year period. At both sites the original copies of Forms 12 and 14 are kept by the hospital managers and a list of those patients placed on a Section 5(2) during the time period was available. The medical records department assisted in the collection of the case notes which were subsequently scrutinised.

The case notes of two patients could not be traced, and in a further two cases copies of the discharge letters that were kept by the secretary of the Responsible Medical Officer (RMO) were all that was available. Where the patients' case notes were available the following data were recorded (a) demographic details; (b) presence or absence of copies of Forms 12 and 14 in the case notes; (c) the grade and psychiatric experience of the doctor who signed Form 12; (d) time and day when the Section 5(2) was implemented; (e) the reasons for the use of the Section 5(2); (f) the primary psychiatric diagnosis, when made, at first contact: (g) a past history of parasuicide or alcohol dependence; (h) the extent of psychiatrists' involvement in the management of patients who have been detained on medical wards and, (i) the medical and legal outcome.

\section{Findings}

During the period 1 January 1990 to 31 December 1994, 28 patients were detained on a Section 5(2). The annual number was greatest in 1994 when nine patients were detained. The case notes of two patients could not be traced, thus our sample comprised 15 males and 11 females. The age range was 22 to 76 years with a mean and median age of 40.7 and 39.5 years respectively.

Where the case notes were available the documentation was generally poor. In only 13/ 25 cases (52\%) were coples of Forms 12 and 14 present in the case notes. In nine out of 25 cases (36\%) Form 12 was signed by a doctor who had no psychiatric experience. In seven of these nine 
cases advice was sought from the duty psychiatrist and on each of these occasions the patient was seen by the liaison psychiatry team. In only two out of these nine cases was the doctor signing Form 12 the patient's RMO.

In 24 cases the timing of the section was recorded in the notes. On $15 / 24$ occasions (63\%) patients were detained outside normal working hours (taken to be Monday to Friday 9am to 5pm).

The commonest reasons for detention under Section 5(2) were absconding (20/26 cases), evidence of a mental illness (10/26 cases). confusion (9/26 cases) and suicidal ideation (9/ 26 cases). In the vast majority of cases patients were detained because of a combination of these reasons, for example the patient was confused. aggressive and trying to leave.

In 23 out of 26 cases a psychiatric diagnosis was made at first contact. The diagnoses were extremely varied ranging from the common syndrome of alcohol withdrawal to such esoteric cases as a paranoid psychosis with accompanying mood disturbance in a patient with Huntington's chorea'. Also worth noting is that three patients in our sample were diagnosed as having a psychotic illness secondary to HIV related brain disease.

The overall conversion rate was 54\% (14/26 cases). In eight cases (31\%) the Section 5(2) was converted to a Section 2 and in 6 cases (23\%) to a Section 3. In five cases (19\%) the 5(2) was allowed to lapse and in seven cases (27\%) it was rescinded following subsequent assessment by a senior psychiatrist or the RMO. Patients whose Sections were invoked by a senior psychiatrist and those who showed evidence of a mental illness or suicidal ideation were more likely to have their Section 5(2) converted to a Section 2 or 3 . Conversely, patients whose Sections were invoked by a junior doctor, where there was evidence of confusion at the time of the assessment or a past history of alcohol dependence, were less likely to have their Section 5(2) converted to a Section 2 or 3.

With regard to the joint management of detained patients, out of the 17 patients who remained on a general ward, four patients $(24 \%)$ were not reviewed by a psychiatrist in the next 24 hours. However, in two of these four cases this was probably because the RMO rescinded the Section 5(2) the following day as the patient's confusion and unwillingness to receive treatment had faded. In 13 out of 17 cases $(76 \%)$ the patient was reviewed by a psychiatrist in the next 24 hours with advice being frequently given about clinical management, particularly about psychotropic medication. In only five out of the 13 cases (38\%) was advice given about the nursing levels of observation.

Nearly all patients (25/26 cases) received some form of psychiatric input following the period of detention. A proportion of patients (11/26 cases) were transferred to a psychiatric ward while others were followed up in out-patients or referred on to the local addictions unit.

\section{Comment}

Over the last 5 years both hospitals have seen an increase in the frequency of use of the Section 5(2) and an encouraging finding was the quick response of psychiatrists to requests for advice. It is surprising, however, that written advice was rarely given about nursing levels of observation of the patient. This is common practice in psychiatric hospitals and perhaps equally important in this environment.

The conversion rate in this study compares fairly favourably with the conversion rates seen in studies conducted in psychiatric units (Joyce et al, 1991; Pourgourides et al, 1992; Mason \& Turner, 1994). In many cases the patient characteristics which appeared to reduce the likelihood that the Section 5(2) would be converted to a Section 2 or 3 were interlinked. In five cases patients presenting out of hours with delirium tremens were all detained by a junior hospital doctor as they were confused, aggressive and trying to leave. Some psychiatrists might argue that, in these cases, the use of the Mental Health Act was inappropriate and the patient should have been brought back to the ward and treated under Common Law.

Rather worryingly in a proportion of cases Section 5(2)s were allowed to lapse without a formal assessment for Section 2 or 3 . This is clearly a breach of Subsection 8.1b of The Code of Practice (DoH, 1993). Also in seven cases the RMO, who was not a consultant psychiatrist. nominated a junior hospital doctor to implement the Section. Paragraph 8.14 of the Code of Practice recommends that "only registered medical practitioners who are consultant psychiatrists should nominate deputies", a point already raised by Vincenti (1993). Also, on two occasions, the Act was clearly contravened when a preregistration house officer signed Form 12.

A basic problem uncovered by this study is the ignorance of doctors, both psychiatric and medical, of the appropriate parts of the Mental Health Act. The Code of Practice and the principles of Duty of Care under Common Law as applying to general hospital in-patients demanding their discharge. Clearly all general hospitals need to develop a policy for medical staff which should be implemented when they believe that an in-patient should be detained on a Section of the Mental Health Act. The policy should include such guidelines as the immediate contacting of the duty psychiatrist when detention is being considered. It should also state that the duty psychiatrist 
should see the patient and if they feel detention under the Mental Health Act is appropriate they must liaise with both senior medical and psychiatric staff. From this point on it would be sensible for the patient to be jointly managed by both medical and psychiatric teams and the Section $5(2)$ could be implemented by either the consultant psychiatrist, their nominated deputy or the Medical RMO. The policy should also encourage a prompt assessment of the appropriateness of proceeding to a Section 2 or 3. No Section 5(2) should be allowed to lapse, this is clearly an abuse of what is essentially a power to hold.

\section{References}

COOPER, S. A. (1992) Section 5(2): who acts as the consultant's nominated deputy? Psychiatric Bulletin. 16, 759-761.

Department of HEALTh (1993) Mental Health Act 1983. London: HMSO.
- (1993) Mental Health Act 1983: Code of Practice. London: HMSO.

JOYCE. J. P., MORRIS, M. B. \& PALLA, S. S. (1991) Section 5(2) audit. Psychiatric Bulletin, 16, 224.

MASON. P. \& TURNER, R. (1994) Audit of the use of doctors' holding power under Section 5(2) of the Mental Health Act 1983. Health Trends, 26, 44-46.

Pourgourides, S. A., Prasher, V. P. \& Oyebode, F. (1992) Use of Section 5(2) in clinical practice. Psychiatric Bulletin, 16, 14-16.

VINCENTI, G. E. P. (1993) Who acts as the consultant's nominated deputy? Psychiatric Bulletin, 17, 771.

*Christopher Buller, Senior Registrar, Department of Adult Psychiatry, Airedale Hospital, Keighley, West Yorkshire BD20 6TD; and David Storer, Consultant Psychiatrist, Rachel Bennett, Clinical Audit Officer, Department of Liaison Psychiatry. Leeds General Infirmary

*Correspondence

\title{
Gaskell Academic Series
}

\section{Interpersonal Factors in Origin and Course of Affective Disorders}

\author{
Edited by Ch. Mundt, M.J. Goldstein, K. Hahlweg and P. Fiedler \\ with the assistance of Hugh Freeman
}

This detailed overview of the latest research on affective disorders brings together authors of international background and repute. Both a theoretical and practical approach to the origin and course of affective disorders is presented, covering specific problems and settings. The principal areas covered are: personality factors, risk and course; social support; marital and family interaction; and intervention.

$\bullet £ 30.00 \bullet 368$ pp. • Hardback • 1996•ISBN 0902241907

Available from good bookshops and from the Publications

Department, Royal College of Psychiatrists, 17 Belgrave Square, London SW1X 8PG (Tel. 0171-235 2351, extension 146)

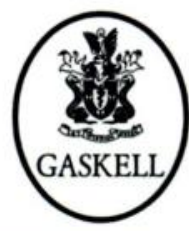

